\title{
A presença da língua portuguesa e da literatura no currículo da educação pré-escolar em Portugal ${ }^{1}$
}

The presence of portuguese language and literature in the curriculum of pre-school education in Portugal

\author{
La presencia de la lengua portuguesa y de la \\ literatura en el currículo de la educación pre-escolar \\ en Portugal
}

Angela Maria Franco Martins Coelho de Paiva Balça²

DOI: http://dx.doi.org/10.20435/serie-estudos.v23i49.1139

\begin{abstract}
Resumo: No ano de 2016, em Portugal, o Ministério da Educação lançou um novo documento curricular para a educação pré-escolar, denominado Orientações Curriculares para a Educação Pré-Escolar. Esse documento veio substituir a um outro, já existente, que datava de 1997. O documento Orientações Curriculares para a Educação Pré-Escolar tem um carácter orientador, sendo uma ferramenta fundamental na prática dos educadores de infância em Portugal. Assim, neste artigo, pretendemos analisar esse documento curricular, tendo em vista apenas a área dedicada à expressão e comunicação, nomeadamente o domínio da linguagem oral e abordagem à escrita. Através de uma leitura crítica e reflexiva desse documento, é nosso objetivo compreender como a área da língua portuguesa e da literatura é perspetivada no currículo oficial para a educação pré-escolar. Como conclusões principais, podemos afirmar que o currículo para a educação pré-escolar, na área da língua portuguesa e da literatura, apresenta um carácter transversal, encarando a criança como construtora das suas aprendizagens.
\end{abstract}

Palavras-chave: Educação Pré-Escolar; Língua Portuguesa; Orientações Curriculares.

Abstract: In 2016, in Portugal, a new curricular document for pre-school education was launched by the Ministry of Education, called Orientações Curriculares para a Educação Pré-Escolar. This

\footnotetext{
${ }^{1}$ Este trabalho foi financiado por Fundos Nacionais através da Fundação para a Ciência e a Tecnologia (FCT) e cofinanciado pelo Fundo Europeu de Desenvolvimento Regional (FEDER), através do COMPETE 2020 - Programa Operacional Competitividade e Internacionalização (POCI) no âmbito do Centro de Investigação em Estudos da Criança da Universidade do Minho (CIEC) com a referência POCI-01-0145-FEDER-007562.

${ }^{2}$ Universidade de Évora/CIEC, Évora, Portugal.
} 
document replaced another one with date of 1997. The document Orientações Curriculares para a Educação Pré-Escolar has a guiding character, being a fundamental tool in the practice of the childhood educators in Portugal. Thus, in this article we intend to analyse this curricular document, considering only the area dedicated to expression and communication, namely the oral language domain and approach to writing. Through a critical and reflexive reading of this document, it is our goal to understand how the area of the portuguese language and literature is seen in the official curriculum for pre-school education. As main conclusions, we can affirm that the curriculum for pre-school education, in the area of portuguese language and literature, presents a transverse character, facing the child as a constructor of their learning.

Keywords: Pre-School Education; Portuguese Language; Curricular Orientations.

Resumen: En el año 2016, en Portugal, fue aprobado, por el Ministério da Educação, un nuevo documento curricular para la Educación Pre-escolar, denominado Orientações Curriculares para a Educação Pré-Escolar. Este documento sustituyó a otro, ya existente, que databa de 1997. El documento Orientações Curriculares para a Educação Pré-Escolar tiene un carácter orientador, siendo una herramienta fundamental en la práctica de los educadores de niños y niñas en Portugal. Así, en este artículo pretendemos analizar este documento curricular, centrándonos en el área dedicada a la expresión y comunicación, en especial el lenguaje oral, si bien realizaremos una aproximación a la lengua escrita. A través de una lectura crítica y reflexiva de este documento, nuestro objetivo es comprender cómo el área de lengua portuguesa y de literatura es representada en el currículo oficial para la educación Pre-escolar. Como conclusiones principales, podemos afirmar que el currículo para la educación Pre-escolar, en el área de la lengua portuguesa y de la literatura, presenta un carácter transversal, facilitando que los niños y niñas sean construtores de sus aprendizajes.

Palabras clave: Educación Pre-Escolar; Lengua Portuguesa; Orientaciones Curriculares.

\section{INTRODUÇÃO}

Desde o ano de 1997 que o Ministério da Educação português colocou à disposição dos profissionais docentes da educação pré-escolar um documento orientador para o seu trabalho, nomeadamente para a sua prática pedagógica, denominado Orientações Curriculares para a Educação Pré-Escolar (doravante Orientações Curriculares). Quando as primeiras Orientações Curriculares foram publicadas, em Portugal, em 1997, acabaram

[...] por se tornar num documento-chave para a educação pré-escolar e tiveram um grande impacto nas práticas pedagógicas de educadores de infância mais jovens, que encontraram aí um caminho mais estruturado para a organização das suas actividades educativas. (DIONÍSIO; PEREIRA, 2006, p. 599).

Volvidos alguns anos, e após meses de reflexão, esse documento deu origem a um outro, com o mesmo título, que entrou em cena no sistema educativo português no ano de 2016. 
Nesse mesmo ano, Balça e Azevedo (2016) publicaram um artigo no qual refletiam sobre o currículo na área da língua portuguesa para a primeira infância em Portugal. Esse artigo recaía sobre uma leitura e análise críticas e reflexivas do documento das Orientações Curriculares publicado em 1997.

No presente estudo, tomamos em consideração o documento das Orientações Curriculares, publicado no ano de 2016, e pretendemos analisá-lo tendo em vista não só a conceção de currículo aí presente, mas também como nele se plasma a área da língua portuguesa e da literatura. O nosso objetivo, neste estudo, é compreender como a área da língua portuguesa e da literatura é perspetivada no currículo oficial para a educação pré-escolar. Sendo assim, seguimos como metodologia a leitura crítica e reflexiva das Orientações Curriculares, numa análise hermenêutica do texto em presença.

Importa realçar que, muito embora saibamos que a língua portuguesa se pode configurar, para as crianças que frequentam a educação pré-escolar, com outros estatutos (língua não materna, língua segunda, língua estrangeira), encaramo-la, neste estudo, como sinónimo de língua materna.

A língua portuguesa é considerada por Mouraz (2003) como uma matriz de identidade pessoal e coletiva e como uma matriz de conhecimento que a converte no eixo central do currículo. Esse entendimento da língua materna já se encontra plasmado na atual Lei de Bases do Sistema Educativo, nomeadamente no seu artigo 47으, ponto 7, assumindo-se na Lei que todas as componentes curriculares contribuem, de modo sistemático, para o desenvolvimento das capacidades das crianças na compreensão e na produção de enunciados orais e escritos em língua portuguesa.

Na verdade, a língua portuguesa configura-se como um instrumento básico de cidadania que possibilita às crianças a integração plena na sociedade onde estão inseridas e um maior sucesso no seu percurso académico. Segundo Reis (2007, p. 7),

[...] o ensino do português é uma questão de cidadania, responsabilidade colectiva que a todos compromete, na casa comum que habitamos como cidadãos com direitos e com deveres cívicos; para mais, esta é uma cidadania compartilhada com outros países e com outros povos, noutras e longínquas partes do mundo.

Nesse sentido, falamos da língua portuguesa nas distintas aceções que ela pode tomar no percurso educativo de uma criança. Assim, a língua é concebida como um instrumento de comunicação, uma vez que é através dela que se 
comunica, em todas as áreas do saber, entre todos os intervenientes, no processo educativo das crianças. A língua materna é igualmente um veículo de aprendizagem, dado que, em todas as áreas do saber, as crianças realizam muitas das suas aprendizagens através da língua; ela é também um veículo, através do qual todas as áreas do saber podem ser/são avaliadas.

A língua é ainda objeto de estudo, no sentido em que ela permite a análise e a reflexão sobre ela própria, levando as crianças a tomarem consciência, de forma progressiva, do modo como se constitui e como se organizam os elementos estruturantes da sua língua materna, desenvolvendo assim a sua consciência linguística.

Enfim a língua pode ser igualmente um objeto de fruição, lúdico, de prazer, de afeto, nomeadamente através da sua vertente literária, que se constitui como

Um lugar que não é lugar, um tempo que não se mede pelo tempo, uma língua que não é a linguagem. Esse lugar, esse tempo e essa língua podem tornar-se objecto de um desejo, permitem pressentir uma forma particular de conhecimento, ou talvez de revelação. (CRÉPU, 2007, p. 56).

Este é o entendimento de língua portuguesa e de literatura que queremos convocar, neste estudo, para a leitura, análise e reflexão do mais recente documento das Orientações Curriculares para a educação pré-escolar.

\section{AS ORIENTAÇÕES CURRICULARES PARA A EDUCAÇÃO PRÉ-ESCOLAR}

Apesar de o currículo para a educação pré-escolar ser enformado por diversos documentos, a nossa atenção, neste estudo, recai sobre as Orientações Curriculares, datadas de 2016. A leitura e a análise desse documento permite-nos perceber que, subjacente a ele, se encontra uma aceção de currículo na linha da noção avançada por Roldão (2008). Estamos perante um documento orientador (e não prescritivo), que dá liberdade de ação aos educadores de infância que nele suportam a sua prática. E é essa liberdade que permite aos educadores de infância refletir e agir, tendo em conta

[...] as melhores maneiras de ensinar, os formatos de organização dos saberes que proporcionem mais e melhor aprendizagem, as formas mais eficazes de se organizarem, as respostas que provem resultar melhor em cada situação. (ROLDÃO, 2008, p. 78).

No Preâmbulo às Orientações Curriculares, assinado pelo Secretário de Estado da Educação, João Costa, reconhece-se um currículo dinâmico, vivo, 
construído no quotidiano, numa relação entre os diversos profissionais e as crianças, com liberdade, autonomia e flexibilidade,

Este é o nível educativo em que o currículo se desenvolve com articulação plena das aprendizagens, em que os espaços são geridos de forma flexível, em que as crianças são chamadas a participar ativamente na planificação das suas aprendizagens, em que o método de projeto e outras metodologias ativas são usadas rotineiramente, em que se pode circular no espaço de aprendizagem livremente. [...] As crianças, neste contexto, planificam o dia, circulam entre as atividades, gerem projetos, experimentam, integram as suas vivências na aprendizagem, são chamadas a desenvolver competências de nível mais elevado, comunicando e criando." (PORTUGAL, 2016, p. 4).

O documento das Orientações Curriculares é agregador do currículo e das práticas pedagógicas dos educadores de infância, não é um programa, mas sim um documento aberto, que aposta no ponto de vista globalizante e numa perspetiva holística, possibilitando aos profissionais uma ação marcada pela independência de pensamento e de expressão.

O atual documento das Orientações Curriculares obedece a uma estrutura que visa auxiliar, quanto a nós, os educadores de infância, na construção e na gestão do currículo da educação pré-escolar. Desse modo, esse documento apresenta três capítulos que se complementam: Enquadramento Geral; Áreas de Conteúdo; e Continuidade Educativa e Transições.

No Enquadramento Geral, as preocupações assentam em três vetores: nos fundamentos e princípios da pedagogia para a infância, na intencionalidade educativa ao construir e gerir o currículo e na organização do ambiente educativo. As Áreas de Conteúdo incidem sobre conhecimentos e atitudes de diversas áreas do saber reconhecidas na sociedade atual. A Continuidade Educativa e Transições debruça-se sobre a continuidade do desenvolvimento e das aprendizagens das crianças, em múltiplos contextos, que importa considerar nos ciclos seguintes de escolaridade.

Esse documento das Orientações Curriculares realça também a importância da unidade em toda a pedagogia para infância. Na verdade, a legislação portuguesa, nomeadamente a Lei de Bases do Sistema Educativo e a Lei-Quadro da Educação Pré-Escolar, apenas considera a educação pré-escolar a partir dos 3 anos, não abarcando a valência de creche (dos 0 aos 3 anos). Todavia esse documento acolhe a Recomendação do Conselho Nacional de Educação, recomendação esta 
que considera que a educação pré-escolar é um direito da criança. Assim, esse documento das Orientações Curriculares chama a atenção para

[...] uma unidade em toda a pedagogia para a infância e que o trabalho profissional com crianças antes da entrada na escolaridade obrigatória tenha fundamentos comuns e seja orientado pelos mesmos princípios. (PORTUGAL, 2016, p. 5).

Nas Orientações Curriculares, assume-se a criança como sendo sujeito e agente do seu processo educativo, sendo a construção do saber marcada pela articulação, pelo desenvolvimento holístico, abordando-se todas as áreas de forma globalizante e integrada. Desenvolvimento e aprendizagem andam de mãos dadas, numa relação estreita, contribuindo ambos e em simultâneo para desenvolvimento físico, cognitivo e emocional da criança, em interação com as experiências proporcionadas pela família e pelo mundo.

Realçamos a importância que, nesse documento, se atribui ao brincar, considerando-se como uma atividade natural da iniciativa da criança. O brincar é encarado como uma atividade que, por ser rica e estimulante, promove o desenvolvimento e a aprendizagem e, por isso mesmo, o educador de infância terá de criar um ambiente onde o brincar é incentivado, observando e envolvendo-se sem interferir. A interação com os outros, estabelecida através do brincar, facilita o desenvolvimento de competências sociais e comunicacionais, com especial ênfase para o progressivo domínio da expressão oral.

Este é, portanto, o contexto onde se desenrola a aquisição, a aprendizagem e o desenvolvimento das crianças no âmbito da língua portuguesa e da literatura na educação pré-escolar.

\section{A PRESENÇA DA LÍNGUA PORTUGUESA E DA LITERATURA NAS ORIENTAÇÕES CURRICULARES PARA A EDUCAÇÃO PRÉ-ESCOLAR}

A Área de conteúdo de Expressão e Comunicação, na qual se integra o Domínio da Linguagem Oral e da Abordagem à Escrita, é por excelência a área/ domínio onde estão alocadas as questões relacionadas com o desenvolvimento, a aquisição e a aprendizagem das crianças no âmbito da língua portuguesa e da literatura, na educação pré-escolar. Todavia uma leitura e análise críticas do documento mostram-nos distintas aceções de língua aí presentes e revelam-nos a importância fundamental da transversalidade da língua portuguesa, não 
se confinando esta ao Domínio da Linguagem Oral e da Abordagem à Escrita já mencionado.

A Área de Expressão e Comunicação engloba múltiplos e distintos Domínios, cuja relação é suportada pelo facto de exigirem à criança a progressiva apropriação de diversas formas de linguagem. Através dessas diversas formas de linguagem, as crianças interagem com os outros, exprimem o seu pensamento e emoções, dão sentido e representam o mundo que as rodeia. A apropriação dessas múltiplas formas de linguagem "permite à criança apropriar-se de instrumentos fundamentais para a aprendizagem noutras áreas, mas, também, para continuar a aprender ao longo da vida" (PORTUGAL, 2016, p. 43).

Todavia o trabalho, a apropriação e o progressivo domínio dessas distintas formas de linguagem são sempre mediados pela língua, que se assume, desse modo, transversal a todo o currículo da educação pré-escolar e a todas as áreas de conteúdo previstas nas Orientações Curriculares.

A questão da transversalidade da língua pode ser olhada sob duas perspetivas: por um lado, a perspetiva do docente; por outro, a das crianças.

Do ponto de vista do educador de infância, tendo em conta a monodocência, não se espera que ele se atenha só às questões relacionadas com a língua materna. Não será possível é ignorar que o educador de infância é, em simultâneo, docente de língua portuguesa e em língua portuguesa e, por isso, tem de ser um utente competente da sua língua, dado que as crianças realizam as suas aprendizagens também, e sobretudo, através da língua em que pensam e falam.

Se tivermos em conta as crianças, para elas "toda a experiência escolar é, em larga medida, uma experiência linguística" (VALADARES, 2003, p. 13). A língua configura-se como um instrumento de comunicação que perpassa todas as áreas de conteúdo e, nesse sentido, ela é de facto transversal a todo o currículo. É através da língua que as crianças fazem as suas aquisições e aprendizagens, é através da língua que elas são avaliadas, é através da língua que elas se expressam e comunicam.

A Língua Portuguesa, através do desenvolvimento das suas competências essenciais, desempenha um papel de relevo na aquisição de saberes nas diversas disciplinas. Só desenvolvendo capacidades ao nível de leitura, compreensão e expressão orais e escritas, em Língua Portuguesa, os alunos estarão aptos a construir a sua aprendizagem, em processos significativos, noutras áreas, e a alcançar o sucesso escolar e social. (VALADARES, 2003, p. 31). 
Assim atendendo a todos esses pressupostos, considerando em particular que o educador de infância é docente em língua portuguesa e atentando que esta é transversal a todo o currículo da educação pré-escolar, centramo-nos na forma como esses aspetos se materializam em todas as áreas de conteúdo das Orientações Curriculares, com exceção para o Domínio da Linguagem Oral e Abordagem à Escrita que será objeto de uma atenção detalhada mais à frente.

As Orientações Curriculares apresentam as seguintes áreas de conteúdo: Área de Formação Pessoal e Social; Área do Conhecimento do Mundo; Área de Expressão e Comunicação.

A Área de Formação Pessoal e Social trata da forma como as crianças se relacionam consigo próprias e com o mundo, num processo de desenvolvimento de atitudes e valores que constituirão as bases de aprendizagens para a vida em sociedade. Nessa Área, é valorada a voz das crianças, sendo particularmente importante a construção de um ambiente onde a criança se sinta valorizada e escutada. A escuta da voz das crianças é fundamental quando falamos da aquisição, do desenvolvimento e da aprendizagem da língua materna. Só num ambiente em que se sinta escutada, a criança poderá ter o desejo de falar, de se exprimir, de comunicar, tendo assim oportunidade de alargar o seu vocabulário, de enriquecer as suas estruturas linguísticas, em suma, de interagir com os outros através da palavra. E, assim, nessa Área, são valorizados o debate e a negociação, a partilha de ideias e de aprendizagens, a autorregulação da aprendizagem e a construção conjunta do pensamento.

Entre outros aspetos, essa Área procura que as crianças tenham a oportunidade de se relacionar com a sua cultura e com a do Outro, contactando com as mais diversas manifestações dessas mesmas culturas. Ora, uma das formas de contactar com as mais distintas culturas é através da sua literatura. Muito embora nessa Área em concreto não haja uma menção clara à literatura ou mesmo às histórias, podemos enquadrá-las nas referências muito evidentes que fazem apelo ao trabalho, ao reconhecimento e à valorização das múltiplas manifestações de cultura, linguagens artísticas e/ou manifestações do património artístico e cultural.

A Área do Conhecimento do Mundo é encarada na educação pré-escolar como uma sensibilização às ciências naturais e sociais. Nesse documento das Orientações Curriculares, preconiza-se que se parta da mobilização de aprendizagens das crianças de todas as outras Áreas, para o trabalho com as ciências 
naturais e sociais "Assim, para estruturar e representar a sua compreensão do mundo, as crianças recorrem a diferentes meios de expressão e comunicação (linguagem oral e escrita [...])" (PORTUGAL, 2016, p. 85).

Pela natureza dessa Área, o recurso ao diálogo, ao debate de ideias, à recolha e organização da informação e à sua comunicação é fundamental. Para tudo isto, a criança socorre-se de várias linguagens, mas sobretudo da linguagem oral e escrita, nas descobertas e na sua comunicação aos colegas, desenvolvendo a oralidade e caminhando nas suas aquisições em termos de literacia emergente. Nas recomendações para os educadores de infância, o documento das Orientações Curriculares menciona que estes poderão utilizar, no trabalho com as crianças, livros e outros documentos de consulta, em papel ou digitais, que as levem à descoberta e ao conhecimento do mundo. Igualmente, nessa Área, é chamada a atenção para o conhecimento e a valorização, por parte das crianças, do património cultural e natural.

Apesar de, igualmente nessa Área, não haver uma menção evidente em relação à literatura ou às histórias, elas são pressentidas no incentivo à descoberta também com o auxílio do livro que, nesse contexto da educação pré-escolar, é muitas vezes o livro de literatura infantil.

A Área de Expressão e Comunicação integra, entre outros, os seguintes Domínios: Domínio da Educação Física; Domínio da Educação Artística; Domínio da Matemática.

O Domínio da Educação Física, tendo em conta uma perspetiva holística, permite à criança o desenvolvimento da consciência e do domínio do seu corpo, numa relação com o espaço, com os objetos e com os outros. A relação desse Domínio com o Domínio da Educação Artística, nomeadamente com a música/ dança, permite às crianças a manipulação de sons e de palavras que potenciam o alargamento da sua capacidade de expressão e de comunicação. O desenvolvimento da linguagem é ainda possibilitado pelas diversas atividades planificadas e pelo jogo, não só pela compreensão de regras, cada vez mais complexas, mas também pela oportunidade de interação com os outros através da linguagem.

O Domínio da Educação Artística abrange os Subdomínios das Artes Visuais, do Jogo Dramático/Teatro, da Música e da Dança. As ligações entre esse Domínio e o Domínio da Linguagem Oral e Abordagem à Escrita são por demais claras. Estas evidências encontram-se, por exemplo, no quadro de aprendizagens que podem ser observadas quando a criança 
Dialoga sobre as diferentes imagens e/ou objetos que aprecia/contacta em diferentes contextos (museus, galerias, outras instituições culturais, natureza, livros online, etc).

Emite opiniões sobre os seus trabalhos, os das outras crianças e sobre diferentes manifestações de artes visuais com que contacta, indicando algumas razões dessa apreciação.

$[\ldots]$

Expõe, discute ideias e propõe soluções para desafios criativos, em jogos dramáticos e representações dramáticas. (PORTUGAL, 2016, p. 50-4).

Na verdade, no Domínio da Educação Artística assumem especial significado as distintas formas de linguagem, não-verbal e verbal. A língua materna possibilita uma verdadeira interação com os outros, num caminho que pretende desenvolver na criança a sua expressão, quando emite opiniões e quando expõe, e a comunicação, quando dialoga e discute as suas ideias.

Se nos centrarmos no Subdomínio da Música, no documento das Orientações Curriculares descortinamos a questão da transversalidade da língua,

Trabalhar as letras das canções relaciona a Música com o desenvolvimento da linguagem, o que passa por compreender o sentido do que se diz, tirar partido das rimas para discriminar os sons, explorar o carácter lúdico das palavras e criar variações da letra original. (PORTUGAL, 2016, p. 55).

De facto, as tarefas propostas para o trabalho entre a música e a língua materna são fundamentais para a aquisição, o desenvolvimento e a aprendizagem da língua, mas também para o desenvolvimento das aquisições literácitas das crianças.

Se, no Domínio da Educação Física, não temos referências concretas à literatura ou às histórias, não queremos deixar de assinalar as menções aos jogos tradicionais que levam as crianças a conhecer e a valorizar o património e que, por vezes, surgem nas histórias lidas/contadas em sala. Já o Domínio da Educação Artística é fértil no apelo que faz aos educadores de infância para o trabalho com o livro, com as histórias, com as letras/poemas das canções, com o texto dramático, tornando a literatura uma presença efetiva.

O Domínio da Matemática centra-se no desenvolvimento de noções matemáticas na criança, noções estas que se iniciam muito precocemente, sendo fundamental que a educação pré-escolar dê continuidade e apoie essas aprendizagens. 
A linguagem é primordial na construção do pensamento matemático bem como na comunicação dos processos matemáticos. Essa comunicação auxilia a criança a organizar e a sistematizar o seu pensamento. Aliás nas sugestões de reflexão para os educadores de infância, surge a questão "De que modo leva as crianças a comunicarem o seu pensamento matemático e a debaterem em pequenos grupos as suas ideias e a forma como resolveram os problemas propostos por elas ou pelo/a educador/a?" (PORTUGAL, 2016, p. 84).

Desse modo, podemos afirmar que, no Domínio da Matemática, se aposta claramente no desenvolvimento da linguagem, no desenvolvimento das competências ligadas à oralidade. Mas também as competências ligadas à literacia emergente são promovidas e mobilizadas. O Domínio da Matemática socorre-se com frequência da literatura infantil para, por exemplo, o desenvolvimento do raciocínio matemático, para o reconhecimento de padrões, para a compreensão da sua repetição. Nesse campo, as letras de canções, a poesia, as histórias podem ser uma mais-valia, pelos refrões, pelas rimas, pelas aliterações.

Centramo-nos agora na Área de Expressão e Comunicação, no Domínio da Linguagem Oral e Abordagem à Escrita. O documento das Orientações Curriculares concebe a aprendizagem da linguagem oral e da linguagem escrita como um processo contínuo, que se desenvolve precocemente em função dos contactos, das interações, das experiências das crianças, em termos linguísticos, com o mundo que as rodeia. Nesse Domínio, é clara a assunção da transversalidade da língua portuguesa

Estas competências são transversais e essenciais à construção do conhecimento nas diferentes áreas e domínios, já que são ferramentas essenciais para a troca, compreensão e apropriação da informação. Por outro lado, esta transversalidade leva também a que todas as áreas contribuam igualmente para a aquisição e o desenvolvimento da linguagem. (PORTUGAL, 2016, p. 60).

Retomando a questão da transversalidade da língua portuguesa, Castro (1995) afirma ser uma falácia comum que todos os docentes (nomeadamente aqueles que não são professores de língua materna) sejam docentes de língua portuguesa. Todavia, para esse investigador, todos os docentes de todas as áreas poderão contribuir para o desenvolvimento e a aprendizagem da língua materna na medida em que podem promover o desenvolvimento de capacidades, como 
usar técnicas de retenção e recuperação da informação, usar dicionários ou enciclopédias, interpretar mapas, gráficos ou diagramas. Acreditamos ser nesse sentido, também, que, no documento das Orientações Curriculares, se afirme a importância das outras Áreas para o desenvolvimento da língua materna. Mas, porque estamos perante um perfil de monodocência, sabemos que, nesse caso, as outras Áreas contribuem também para a aprendizagem da língua materna, para a expansão do vocabulário, para o enriquecimento das estruturas linguísticas das crianças, para a aquisição das suas competências literácitas.

O Domínio da Linguagem Oral e Abordagem à Escrita divide-se na Linguagem Oral e na Abordagem à Escrita. Apesar do próprio documento justificar essa separação, concordamos com as observações de Balça e Azevedo (2016, p. 147) quando afirmam que

Se estas divisões podem ajudar o profissional na leitura do documento, elas não favorecem, quanto a nós, a compreensão de que a aquisição e o desenvolvimento da linguagem oral são fundamentais para o desenvolvimento da literacia emergente e consequente apropriação da leitura e da escrita.

Esse documento das Orientações Curriculares considera, dentro da Linguagem Oral, duas grandes componentes - a comunicação oral e a consciência linguística.

No que à comunicação oral diz respeito, afirma-se que compete ao educador de infância criar, na sua sala, um clima de comunicação entre ele e as crianças e entre as próprias crianças. O ambiente educativo e linguístico da sala tem de ser rico e estimulante, adotando o educador de infância o papel de andaime, empenhando-se em promover o interesse da criança em comunicar, proporcionando-lhe diferentes situações de comunicação e possibilitando-lhe um progressivo domínio da sua língua materna, como o alargar do vocabulário, a construção de frases mais corretas e complexas ou mesmo a apropriação das diferentes funções da linguagem.

Em relação à consciência linguística, aposta-se no progressivo entendimento, por parte das crianças, de que a sua língua materna é um instrumento de comunicação, mas é também um objeto de reflexão, colocando-se a ênfase num trabalho que promova a emergência da consciência fonológica, da consciência da palavra e da consciência sintática. Para o desenvolvimento dessas três dimensões, o documento preconiza a exploração do carácter lúdico da linguagem, 
permitindo às crianças descobrir o prazer em brincar com as palavras, com os seus sons, desvendando as relações entre elas, tendo como grandes suportes as rimas, as lengalengas, os trava-línguas, as adivinhas, a poesia.

O documento das Orientações Curriculares considera, dentro da Abordagem à Escrita, três grandes componentes - funcionalidade da linguagem escrita e sua utilização em contexto; identificação de convenções da escrita; e prazer e motivação para ler e escrever. A questão do trabalho com a escrita, na educação pré-escolar, deve ser encarada da seguinte forma: "Não se trata de uma introdução formal e "clássica", mas de facilitar a emergência da linguagem escrita através do contacto e uso da leitura e da escrita, em situações reais e funcionais associadas ao quotidiano da criança." (PORTUGAL, 2016, p. 66).

No que à funcionalidade da linguagem escrita e sua utilização em contexto diz respeito, aposta-se na apropriação, por parte das crianças, da funcionalidade da escrita, levando-as a responder à questão para que serve a escrita. O contacto com os mais variados materiais impressos, com intencionalidade, em situações reais e funcionais, vai permitir à criança compreender as funções e a especificidade do texto escrito, familiarizando-a com as características e convenções da escrita e contribuindo para a sua utilização de forma cada vez mais autónoma.

Em relação à identificação de convenções da escrita, aposta-se na compreensão, por parte das crianças, de que a escrita é um código com regras próprias. As tentativas de escrita da criança deverão, obrigatoriamente, ser valorizadas pelo adulto, não esquecendo que a primeira forma de escrita é o desenho das crianças e que aprender a escrever o próprio nome tem um sentido afetivo fundamental para a criança. Será basilar que as crianças tenham a ocasião de imitar a escrita e a leitura, colocando ao alcance destas materiais de qualidade. O educador de infância terá de criar um bom ambiente literácito, onde as oportunidades de escrita e de leitura, que possibilitem às crianças compreender que a escrita é um código com várias convenções próprias e com distintas funções, sejam uma realidade.

No que diz respeito a prazer e motivação para ler e escrever, entramos no âmbito da construção do projeto pessoal de leitor e escritor. O educador de infância terá de criar um ambiente literácito que promova o envolvimento com a leitura e a escrita, o afeto, a motivação, a disposição para com a aprendizagem dessas competências, de modo que as crianças consigam encontrar razões pessoais para se envolverem positivamente com a leitura e com a escrita. 


\section{CONSIDERAÇÕES FINAIS}

Neste estudo, procurámos fazer uma leitura e análise críticas e reflexivas do documento das Orientações Curriculares para a Educação Pré-Escolar, publicado em Portugal, em 2016. Esse documento constitui-se como um documento orientador para os profissionais docentes da educação pré-escolar, nomeadamente no que diz respeito à sua prática pedagógica.

Nesse documento, realçámos a noção de currículo que lhe estava subjacente, tendo encontrado um entendimento de currículo agregador, com grande margem de liberdade, de autonomia, de flexibilidade, procurando encarar todas as áreas, na educação pré-escolar, numa perspetiva holística.

A área da língua portuguesa e da literatura surgem-nos no documento com uma perspetiva transversal. Essa transversalidade é claramente assumida na Área de Expressão e Comunicação, no Domínio da Linguagem Oral e Abordagem à Escrita. Todavia, numa leitura e análise mais atenta e profunda das Orientações Curriculares, notamos que a língua marca a sua presença em todas as áreas de conteúdo do documento; quanto à literatura, não estando tão visível em todas as áreas de conteúdo, podemos ainda assim pressenti-la.

O educador de infância terá de ser um utente competente da sua língua, uma vez que, mesmo num regime de monodocência, ele é em simultâneo um docente de língua portuguesa e em língua portuguesa.

Para terminar, retomamos as palavras de Valadares (2003), sobre a necessidade de se assumirem as tarefas de educação linguística como um projeto coletivo, transversal: as crianças "precisam de desenvolver capacidades para funcionar, efectivamente, com a língua escrita e falada, então temos de assumir as tarefas de educação linguística como projecto colectivo, transversal" (VALADARES, 2003, p. 13).

\section{REFERÊNCIAS}

BALÇA, A.; AZEVEDO, F. O currículo na área da língua portuguesa para a primeira infância em Portugal. Nuances: Estudos sobre Educação, Presidente Prudente, SP, v. 27, n. 3, p. 139-54, set./dez. 2016. Disponível em: <http://revista.fct.unesp.br/index.php/Nuances/ article/viewFile/4268/3663>. Acesso em: 9 jun. 2017.

CASTRO, R. V. Todos os professores são professores de Português. Para a crítica de uma falácia comum. In: PACHECO, J.; ZABALZA, M. (Org.). A avaliação dos alunos nos ensinos 
básico e secundário. Braga, Portugal: Instituto de Educação e Psicologia, Universidade do Minho, 1995. p. 97-102.

CRÉPU, M. Esse vício ainda impune. In: STEINER, G. O silêncio dos livros. Lisboa: Gradiva, 2007. p. 53-71.

DIONÍSIO, M. L.; PEREIRA, I. A educação pré-escolar em Portugal. Concepções oficias, investigação e práticas. Perspectiva, Florianópolis, v. 24, n. 2, p. 597-622, jul./dez. 2006. Disponível em: <https://periodicos.ufsc.br/index.php/perspectiva/article/ view/1664/1412>. Acesso em: Acesso em: 8 jun. 2017.

MOURAZ, A. Prefácio. In: VALADARES, L. Transversalidade da língua portuguesa. Porto, Portugal: Edições Asa, 2003. p. 9-10.

PORTUGAL. Ministério da Educação. Orientações Curriculares para a Educação PréEscolar. Lisboa, 2016. Disponível em: <http://www.dge.mec.pt/ocepe/sites/default/files/ Orientacoes_Curriculares.pdf>. Acesso em: 9 jun. 2017.

REIS, C. Apresentação de conferência. In: CONFERÊNCIA INTERNACIONAL SOBRE O ENSINO DO PORTUGUÊS, 2007, Lisboa. Actas... Lisboa: Ministério da Educação, 2007. p. 7-11.

ROLDÃO, M. C. Gestão do currículo e avaliação de competências. As questões dos professores. Lisboa: Editorial Presença, 2008.

VALADARES, L. Transversalidade da língua portuguesa. Porto, Portugal: Edições Asa, 2003.

\section{Sobre a autora:}

Angela Maria Franco Martins Coelho de Paiva Balça: Doutora em Ciências da Educação. Docente da Universidade de Évora. Investigadora do Centro de Investigação em Estudos da Criança (CIEC), Universidade do Minho, Portugal.

E-mail:apb@uevora.pt

\section{Recebido em fevereiro de 2018 \\ Aprovado em maio de 2018}


